\title{
Aplicativo móvel para apoiar o processo de ressocialização dos egressos do sistema prisional brasileiro
}

\author{
Mobile app to support the Brazilian prison system inmates' resocialization process
}

Emille Catarine Rodrigues Cançado, Tiago Barros Pontes e Silva, Ana Mansur de Oliveira, Virginia Tiradentes Souto, Edna Dias Canedo

sistema prisional, ressocialização, design de informação, design de interação, aplicativo móvel

O sistema prisional brasileiro possui uma abordagem punitiva cujo foco é o controle da população carcerária. Essa abordagem, que negligencia o processo de ressocialização do egresso, acaba por incapacitá-lo, já que, mesmo em situação de liberdade, o processo de reinserção se torna extremamente penoso. O presente artigo traz um delineamento do panorama geral do sistema prisional no Brasil e busca responder como um sistema interativo pode auxiliar o egresso em seu processo de ressocialização. Em especial, são discutidas dificuldades em relação à emissão e/ou regularização do título de eleitor e suas consequentes adversidades, além de como o aplicativo Escritório Social Virtual busca apoiar o egresso na emissão de sua documentação básica.

prison system, resocialization, information design, interaction design, mobile app

The Brazilian prison system has a punitive approach that focuses on the control of the prison population. This approach neglects the inmate resocialization process, incapacitating him because, even in a freedom situation, the reintegration process becomes extremely arduous. This article provides an outline of the general panorama of the prison system in Brazil and seeks to answer how an interactive system can help inmates in their resocialization process. Are discussed the difficulties related to the emission and/or regularization of the voter registration and its consequent adversities, in addition to how the Virtual Social Office app seeks to support the inmates in the emission of their basic documentation.

\section{Introdução}

No Brasil, do ano 2000 até o ano 2020, o número de detentos do sistema prisional cresceu consideravelmente, passando de 232.755 para 759.518 , conforme dados do Departamento Penitenciário Nacional (Depen). Esse sistema tinha, em seu projeto moderno, o objetivo de corrigir o carcerário, devolvendo para a sociedade um indivíduo reeducado, recuperado e com grande possibilidade de ressocialização (Figueiró \& Dimenstein, 2016). Porém, o sistema prisional contemporâneo possui abordagem com foco no controle do preso, resultado do desinvestimento em políticas sociais (Wacquant, 2003). A precariedade dessa abordagem influencia não apenas na grande dificuldade de ressocialização do egresso, mas também em altas taxas de reincidência criminal (Fischer \& Abreu, 1987).

Anais do $10^{\circ} \mathrm{CIDI}$ e $10^{\circ} \mathrm{CONGIC}$

Kelli C.A.S. Smythe, Rafael de Castro Andrade (orgs.)

Sociedade Brasileira de Design da Informação - SBDI

Curitiba | Brasil | 2021
Proceedings of the $10^{\text {th }} \mathrm{CIDI}$ and $10^{\text {th }}$ CONGIC

Kelli C.A.S. Smythe, Rafael de Castro Andrade (orgs.)

Sociedade Brasileira de Design da Informação - SBDI Curitiba | Brazil | 2021 
Quanto ao processo de ressocialização, pode-se afirmar que é penoso. Conforme aponta Carvalho Filho (2012), a liberdade do cárcere difere muito da ilusão muitas vezes criada pelo ex-preso, tornando-se um processo em que lhe falta moral e faz desse indivíduo uma fonte de perigo para a sociedade, privando-Ihe de oportunidades de reintegração social. Entre as dificuldades encontradas pelo egresso no processo de ressocialização, uma das mais incapacitantes é a dificuldade da conquista de um emprego formal, que é agravada por diversas razões, sendo uma delas a dificuldade de emissão/regularização do título de eleitor.

Desta forma, foram criados os Escritórios Sociais em uma tentativa de mitigar os efeitos desse sistema prisional punitivo e auxiliar o egresso em seu processo de ressocialização. Localizados em alguns estados da federação, esses estabelecimentos visam atender demandas específicas da população egressa do sistema prisional brasileiro. Porém, os Escritórios Sociais não estão disponíveis em todos os estados da federação, o que limita o apoio à ressocialização desse público.

Observando esse contexto, surge o problema: como um sistema interativo pode apoiar o egresso no processo ressocialização, em especial a emissão/regularização de sua documentação?

Buscando responder a esse problema de pesquisa, neste artigo são abordados aspectos do design da informação e de interação aplicados à criação do aplicativo Escritório Social Virtual, que busca replicar, no ambiente virtual, as funções e atividades realizadas nos Escritórios Sociais físicos. Além disso, o artigo busca levantar uma discussão acerca da emissão e/ou regularização de documentação para o egresso, em especial o título de eleitor.

\section{O processo de ressocialização do público egresso do sistema prisional}

A maior parte da população carcerária é composta por excluídos sociais, em especial negros e pessoas com baixa escolaridade (Monteiro \& Cardoso, 2013; Infopen, 2017). Almeida e PaesMachado (2013) acrescentam o rótulo dado pela sociedade aos prisioneiros: de pessoas más, fortes, estranhas à sociedade. Isso implica que a sociedade não os vê como vítimas da falta de investimento em políticas públicas por parte do governo, o que estimula os sentimentos vingativos que são alimentados com pesadas punições aplicadas no ambiente carcerário e na marginalização desse indivíduo quando encontra-se em liberdade.

Sendo assim, a falta de apoio da sociedade torna o processo de ressocialização demasiadamente penoso. Nesse período, o egresso enfrenta as mais diversas dificuldades, muitas delas relacionadas à falta de oportunidades e à marginalização que sofrem por se encontrarem na posição de ex-presidiário.

Com isso, não é de se impressionar que, dentre os desejos da pessoa egressa que busca a ressocialização, a vontade de conseguir um emprego se destaca. Porém, em grande parte dos casos, são muitas as dificuldades que devem ser superadas para que exista a possibilidade dessa conquista. Além da marginalização já mencionada, a falta de escolaridade e de conhecimentos básicos sobre o mercado de trabalho são alguns exemplos. 
Além disso, questões como regularização e/ou emissão de documentos, em especial o título de eleitor, também são um grande empecilho para que esses egressos consigam uma vaga de emprego formal. A solução para esse caso em geral não é simples, uma vez que pode envolver o pagamento da pena de multa.

\section{Sobre a Pena de multa}

Conforme afirma Mergulhão (2005), "a pena de multa consiste na condenação, em determinada soma em dinheiro, pela transgressão a um tipo penal". O cálculo dessa pena se dá no sistema de dias-multa, sistema esse que garante que o valor esteja sempre atrelado ao salário-mínimo e, portanto, atualizado.

Esse valor é direcionado ao fundo penitenciário e tem quantia fixada na sentença do apenado. Conforme disposto no artigo 49 do Código Penal (2017), tem valor mínimo de 10 dias-multa e máximo de 360 dias-multa. O valor do dia-multa, por sua vez, é fixado pelo juiz e tem como mínimo um trigésimo do maior salário-mínimo e máximo de cinco vezes esse salário. A fixação desse valor não pode ser feita de maneira arbitrária, devendo-se levar em consideração a culpabilidade do réu e a condição financeira do indivíduo julgado.

Quanto à aplicação da pena de multa, pode ser feita das seguintes formas:

(1) isoladamente, sendo a pena única (exemplo nos casos previstos na Lei de Contravenções Penais);

(2) cumulativamente, com a pena privativa de liberdade (a exemplo do artigo 157 do Código Penal, quando trata do crime de roubo, prevendo em seu preceito secundário a pena de reclusão de 4 a 10 anos, e multa); (3) alternativamente à pena privativa de liberdade (a exemplo do crime de perigo de contágio venéreo, previsto no art. 130, cominado pena de detenção, de três meses a um ano, ou multa); (4) em substituição à pena privativa de liberdade, quer sozinha (condenação igual ou inferior a 1 (um) ano, desde que presentes as condições de favorabilidade do art. 59 do CP), quer em conjunto com a pena restritiva de direitos, independentemente de cominação da Parte Especial" (Cassiano, 2017, pp. 8-9).

Deste modo, a pena de multa pode ser considerada uma vantagem em casos que acarreta economia ao Estado, uma vez que não priva o condenado de sua liberdade, economizando em verba para fins carcerários e, além disso, recebe um valor dos condenados em questão. Além disso, poupa esses indivíduos de passarem pela experiência de serem presos, o que evita o penoso processo de ressocialização.

Porém, neste estudo, cabe ressaltar a segunda forma, na qual a pena de multa é aplicada cumulativamente à pena privativa de liberdade. Nesta modalidade, temos o indivíduo que, além de ser privado de sua liberdade, possui também a obrigação de quitar o valor fixado pelo juiz. Sendo assim, é preciso considerar a desvantagem da pena de multa: na maioria das vezes, o valor fixado é muito baixo, de forma que o gasto relativo à cobrança supera o valor do débito (Cassiano, 2017). Esse mesmo valor, por sua vez, pode ser inacessível para o julgado, que muitas vezes vive em condições financeiras precárias. Desta forma, essa pena, que deve ser paga em até 10 dias, muitas vezes permanece em aberto por incapacidade de pagamento por parte do apenado e/ou falta de cobrança. Vale ressaltar que o não pagamento da pena de multa não pode levar à prisão. Essa dívida, porém, faz com que o egresso do 
sistema prisional não possa emitir e/ou regularizar o seu título de eleitor até a sua quitação, privando-Ihe de sua cidadania.

\section{Consequências da não regularização e/ou emissão do título de eleitor}

O título de eleitor, além de garantir a cidadania do indivíduo através do direito de participação da vida política, tem um papel fundamental na vida do egresso. Para a admissão em uma vaga de emprego formal (nos moldes da Consolidação das Leis do Trabalho - CLT), é comum a solicitação do título de eleitor para a admissão.

Desta forma, o egresso que, por qualquer motivo, não pôde quitar sua pena de multa, se encontra impedido de assumir essa vaga por não ter a oportunidade de emitir ou regularizar o seu título de eleitor. Sem um emprego, não tem a oportunidade de conseguir o valor para quitar sua dívida. Se vê, então, em uma situação em que dificulta a sua recuperação por vias legais, muitas vezes cedendo à criminalidade e correndo o risco de se tornar reincidente do sistema prisional.

O que muitos egressos desconhecem, é que um advogado ou defensor pode solicitar na justiça tanto o parcelamento da pena de multa quanto a liberação do título de eleitor (Ferreira, Oliveira \& Vieira, 2020). Sendo assim, podem buscar a Defensoria Pública do seu estado e solicitar assessoria jurídica gratuita, de forma a recuperar seus direitos como cidadão antes do pagamento da pena de multa.

Nesse sentido, o aplicativo Escritório Social Virtual busca trazer essa informação para o público egresso com o objetivo de apoiar na resolução dessa dificuldade e aumentar as possibilidades da conquista de um emprego. Essa ação, consequentemente, poderia reduzir as taxas de reincidência criminal e garantir uma melhor qualidade de vida para o público-alvo em questão.

\section{Sobre o Design da Informação}

O design da informação "é a definição, planejamento, e modelagem dos conteúdos de uma mensagem e do ambiente em que é apresentada, com a intenção de satisfazer as necessidades de informação dos receptores pretendidos" (Internacional Institute of Information Design, 2000). Para Coates e Ellison (2014), o design da informação é imprescindível para o cotidiano de um indivíduo, uma vez que facilita a compreensão de informações complexas e poupa tempo e esforço na transmissão de mensagens.

Petterson $(2002 ; 2016)$ define quatro princípios essenciais do design da informação, cada um deles envolvendo uma série de subprincípios. São eles:

- Princípios funcionais: definição do problema, provisão de estrutura, provisão de clareza, provisão de simplicidade, provisão de ênfase e provisão de unidade.

\footnotetext{
${ }^{1}$ Tradução dos autores.
} 
- Princípios administrativos: acesso à informação, custos de informação, ética de informação e garantia de qualidade.

- Princípios estéticos: harmonia e proporção estética.

- Princípios cognitivos: facilitação da atenção, facilitação da percepção, facilitação do processamento e facilitação da memória.

De acordo com o autor, a utilização desses princípios auxilia o designer a planejar a informação de forma clara e adequada para seus receptores. Essa informação, apresentada em uma mensagem, é transmitida por um meio pelo provedor de informação para um ou mais receptores de informação.

A efetividade e compreensão da mensagem, por sua vez, depende de diversos fatores, como por exemplo: qual é o meio em que está sendo propagada, como a informação se apresenta em termos de linguagem/leiaute e quanto tempo o usuário terá disponível para interagir com a mensagem. Deve-se lembrar que cada meio de transmissão possui vantagens e desvantagens para a transmissão de determinada mensagem, e cabe ao designer escolher o meio que melhor se ajusta à mensagem em questão.

É importante também realizar uma boa definição do perfil dos receptores, uma vez que suas características influenciam a forma como a informação será interpretada. Dados como idade, cultura, gênero e fatores socioeconômicos podem ser importantes para guiar o designer na forma em que irá direcionar a mensagem para maximizar a chance de compreensão do usuário final da maneira que foi planejada.

O contexto no qual a mensagem se apresenta pode também influenciar dramaticamente a forma como ela é percebida e interpretada. Sendo assim, pode ser necessário que o usuário considere não apenas o contexto interno de transmissão da mensagem, mas também o externo.

No caso do sistema prisional, é preciso considerar que o público-alvo é extremamente diverso, com uma grande variedade de perfis e necessidades (Sapori et al., 2017; Monteiro \& Cardoso, 2013). Sendo assim, a informação precisa ser apresentada de maneira que garanta fácil compreensão tanto de usuários mais instruídos como de usuários com baixa alfabetização. Além disso, é necessário que o aplicativo garanta unidade em todas as funcionalidades, a fim de evitar que o usuário necessite aprender diferentes comportamentos para diferentes funcionalidades. É necessário enfatizar informações principais de maneira a facilitar a compreensão e navegação do usuário pelo aplicativo.

Não obstante, para a transmissão da informação, é relevante se planejar as estruturas narrativas de interação humana mediadas pelos artefatos tecnológicos. Para Rogers et al. (2013), o design de interação "envolve trabalhar nos requisitos, conceber uma solução, produzir uma versão interativa da solução e avaliá-la". É importante ressaltar que esse processo não necessita ser linear, podendo adotar uma abordagem iterativa: com fazes de expansão (descoberta e desenvolvimento) e delimitação (definição e entrega), como pode ser visto na representação do duplo diamante, descrito por Pinheiro e Alt (2011).

Outro ponto importante de ser observado é que o envolvimento do usuário auxilia na iteratividade do processo, tanto no início (com a coleta de requisitos) quanto após a proposta 
de uma solução (com testes de usabilidade). Em todo o processo de design, é preciso ter clareza de que o produto em desenvolvimento busca satisfazer uma necessidade de um determinado público-alvo, e por isso é importante ter como principal foco o comportamento dos usuários que representam esse público em questão. É o feedback do usuário que faz com que o designer descubra novos requisitos durante o processo, além possibilitar a recepção de novas informações que podem envolver alterações na solução inicialmente proposta.

Diversas metodologias podem ser aplicadas em cada uma das fases do processo. Para coleta de requisitos, uma alternativa válida é a realização de entrevistas com usuários que representem o público-alvo do produto a ser idealizado. Para o processo de desenvolvimento do produto, o uso de protótipos para a aplicação de testes de usabilidade permite ao designer acompanhar o usuário no uso da versão de teste da solução proposta e, com isso, identificar possíveis falhas e potenciais melhorias antes do lançamento do produto.

O uso dessas metodologias, então, deve ser aplicado a fim de construir uma solução que seja, de preferência, de fácil e agradável utilização, além de ser capaz de transmitir a informação de maneira eficaz, eficiente e agradável.

\section{0 projeto do aplicativo Escritório Social Virtual}

O presente capítulo apresenta o projeto do aplicativo, organizado nas sessões de metodologia, definição das principais funcionalidades e testes iniciais de usabilidade.

\section{Metodologia}

A construção do aplicativo foi orientada pelas abordagens de design descritas anteriormente. Primeiramente, para a coleta de requisitos, foi definido o público-alvo do aplicativo, que consiste em egressos do sistema prisional com variados perfis de idade, sexo, alfabetização e nível de familiaridade com aplicativos móveis.

Com isso, foram utilizados dois principais métodos para a coleta de informações: entrevistas e revisão de literatura, sintetizados a seguir. As informações coletadas permitiram a definição das funcionalidades que seriam disponibilizadas no aplicativo de acordo com a necessidade dos usuários. Essas funcionalidades guiaram o desenvolvimento do aplicativo e permitiram os primeiros testes de validação com usuários para eventuais ajustes e refinamentos antes do lançamento do aplicativo gratuito nas lojas Google Play e Apple Store. É importante ressaltar que esse processo foi iterativo: ou seja, a equipe responsável pela coleta de requisitos e desenvolvimento do aplicativo se permitiu avançar ou regredir nas fases citadas conforme julgou necessário.

Em uma primeira etapa do projeto, foram realizadas entrevistas semiestruturadas com três principais públicos: stakeholders do Conselho Nacional de Justiça (CNJ), egressos do sistema prisional brasileiro e funcionários do Escritório Social do Espírito Santo. As entrevistas com os stakeholders do $\mathrm{CNJ}$, em um primeiro momento, auxiliaram os pesquisadores a 
compreenderem melhor o panorama geral do sistema prisional e quais eram as expectativas gerais em relação ao aplicativo.

Já as entrevistas com egressos e funcionários do Escritório Social do Espírito Santo foram todas intermediadas por funcionários do $\mathrm{CNJ}$, que efetuaram a escolha e convite dos entrevistados, avaliaram e aprovaram o roteiro de perguntas e participaram integralmente das entrevistas. Além disso, foi solicitada a permissão dos entrevistados para gravação e uso das informações coletadas para o desenvolvimento do aplicativo e pesquisas. Essas entrevistas permitiram a validação do conteúdo levantado com os stakeholders do CNJ, além da coleta de novos requisitos. De maneira geral, essas entrevistas foram essenciais para que a equipe de desenvolvimento do aplicativo compreendesse o contexto atual do egresso do sistema prisional brasileiro, quais suas principais necessidades e quais caminhos trilham para a resolução de seus problemas.

Em uma segunda etapa do projeto, foram consultados relatos de pesquisa que auxiliassem a compreender o cenário do sistema prisional brasileiro contemporâneo, a fim de validar e complementar os conhecimentos já adquiridos no processo de entrevistas. Essas revisões trouxeram aos pesquisadores maior conhecimento acerca do tratamento dado ao indivíduo enquanto carcerário (Almeida \& Paes-Machado, 2013; Assis, 2007) e, consequentemente, do caráter punitivo do sistema. Foi possível também compreender mais sobre o perfil desse público (Monteiro \& Cardoso, 2013; Figueiró \& Dimenstein, 2016), dificuldades enfrentadas após a saída da prisão (Carvalho Filho, 2012) e fatores sociais determinantes para a reincidência criminal (Figueiró \& Dimenstein, 2016; Sapori, Santos \& Maas, 2017). Esses conhecimentos também impactaram na seleção de funcionalidades do app, já que o objetivo é aumentar as possibilidades de ressocialização e consequentemente diminuir as taxas de reincidência criminal.

\section{Seleção de funcionalidades}

Para a seleção de funcionalidades, foram utilizados diversos princípios essenciais do design de informação de Petterson (2002; 2016), conforme citado na seção 3. Considerando o subprincípio de acesso à informação, que leva em consideração fatores como formas de armazenamento, facilidade de acesso e segurança de informações, optou-se por não exigir do usuário informações pessoais.

Desta forma, o usuário não precisa se identificar para fazer uso do aplicativo. Para melhor navegação, ele pode, de maneira opcional, permitir o acesso à localização, o que faz com que possa identificar os endereços ordenados por proximidade à sua localização atual. Caso opte por não compartilhar esse dado, ainda consegue acessar as informações ordenadas por ordem alfabética para a cidade selecionada. É importante frisar que o aplicativo não armazena esses dados para evitar o vazamento de quaisquer dados sensíveis. Essa informação é compartilhada ao usuário logo no primeiro acesso (Figura 1), para que ele possa optar por compartilhar ou não a sua localização atual. 
Figura 1: Modal de permissão ao acesso à localização.

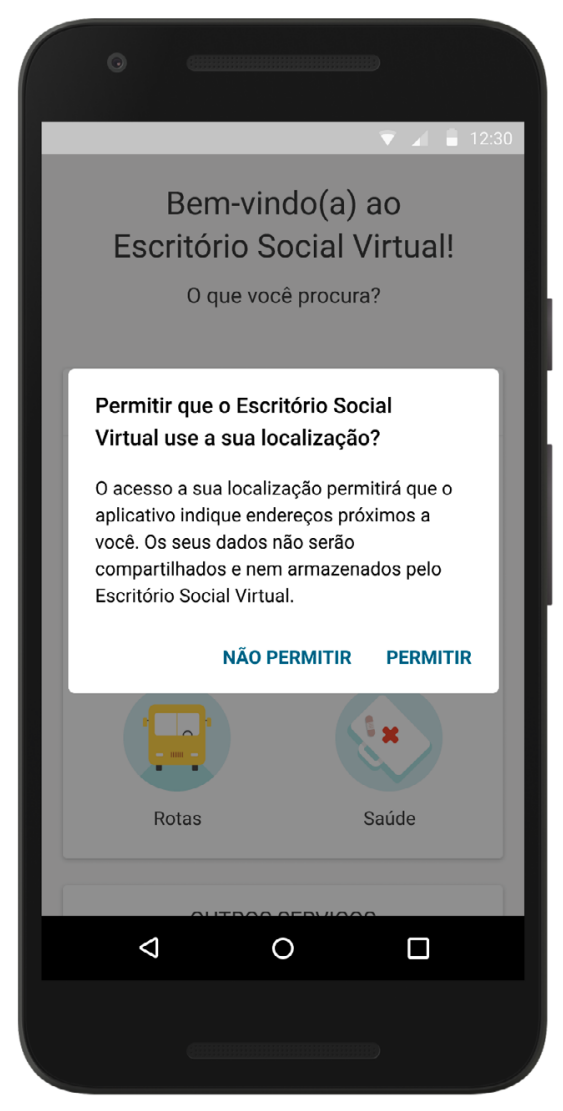

Além disso, foram selecionadas para o aplicativo apenas funcionalidades que fornecessem conteúdo útil para o usuário. Desta forma, uma funcionalidade amplamente solicitada por todos os egressos entrevistados, que era a disponibilidade de vagas de trabalho, não foi contemplada no aplicativo uma vez que os idealizadores do aplicativo não obtiveram sucesso nas tentativas de firmar parcerias com possíveis empregadores.

Por outro lado, outra funcionalidade também solicitada pelos entrevistados, que foi a disponibilidade de cursos profissionalizantes de maneira gratuita, foi incluída no aplicativo graças à parceria firmada entre o $\mathrm{CNJ}$ e a Kroton, uma organização educacional privada que forneceu acesso gratuito à uma lista de cursos profissionalizantes para usuários do aplicativo.

Neste artigo, a fim de responder como um sistema interativo pode apoiar o egresso no seu processo de ressocialização, em especial no caso da emissão e/ou regularização de sua documentação, trataremos com mais detalhes da funcionalidade "Documentação", que visa informar ao egresso como emitir e/ou regularizar sua documentação básica, incluindo o título de eleitor.

\section{Desenvolvimento da funcionalidade "Documentação"}

Como já abordado no tópico 2, a não emissão e/ou regularização da documentação básica, em especial o título de eleitor, pode trazer diversas dificuldades para o egresso do sistema prisional em seu processo de ressocialização. 
Para esse público, muitas vezes a locomoção pela cidade é penosa, em casos em que não possuem transporte próprio e se encontram financeiramente impossibilitados de utilizar o transporte público. Sendo assim, o fácil acesso a informações que possam evitar a locomoção e/ou evitar erros que possam levar o egresso a ter que refazer o trajeto podem ser valiosas.

Além disso, informações adicionais, como onde buscar apoio em caso de maiores dificuldades, também são de grande utilidade para o público egresso. A Figura 2 apresenta a tela inicial dessa funcionalidade.

Figura 2: Tela inicial da funcionalidade "Documentação".
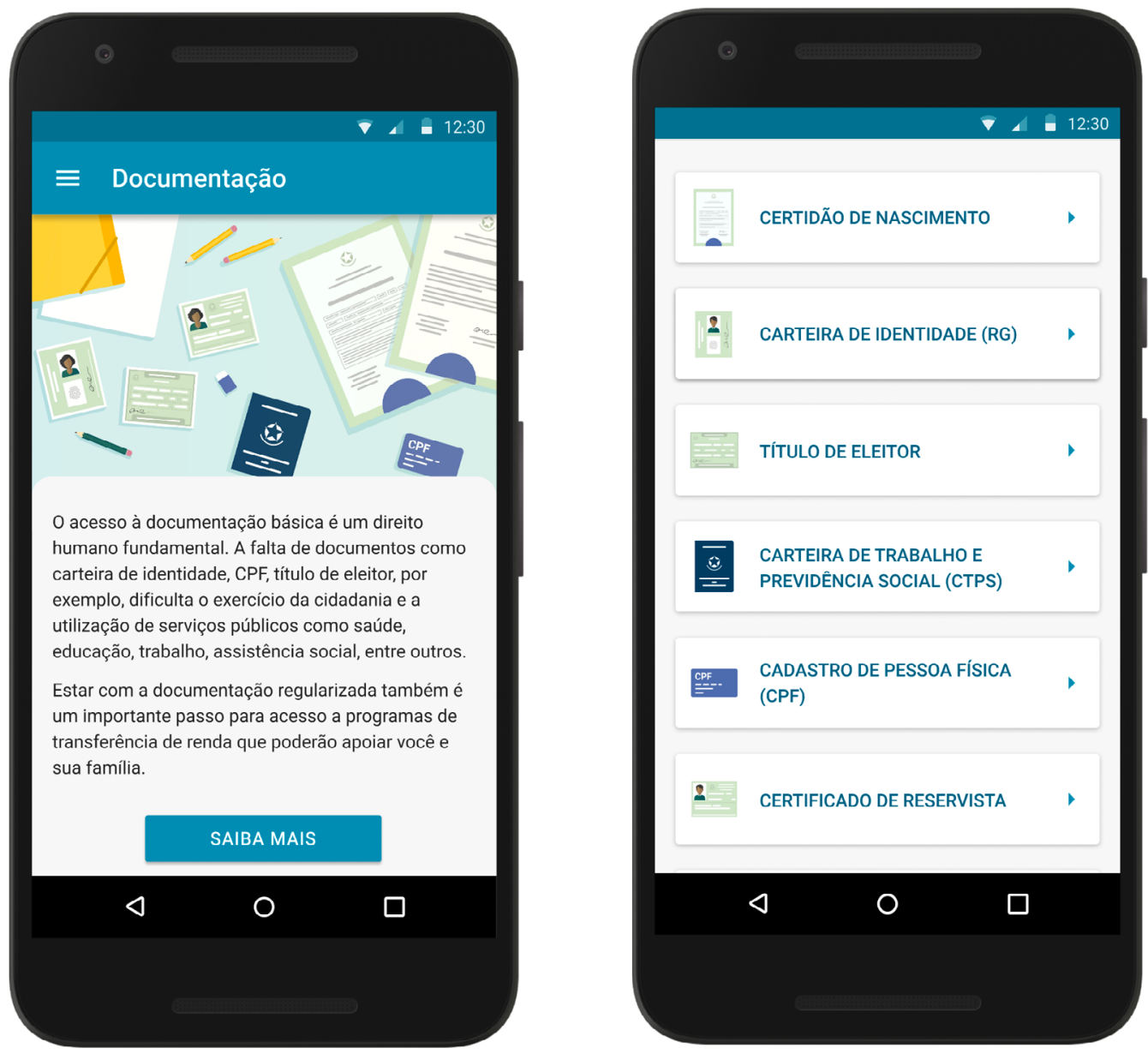

Na Figura 2, na imagem à esquerda, o banner com documentos ilustrados enfatiza o conteúdo abordado na seção, que está descrita no cabeçalho do aplicativo. O texto introdutório informa ao usuário a importância da regularização da sua documentação. $\mathrm{Na}$ imagem da direita, que representa o restante da tela, o usuário acessa lista categorizada por documento, com representações em ícones para enfatizar o significado já descrito em texto. O clique revela ao usuário maiores detalhes.

Para o detalhamento das documentações (Figura 3), algumas questões básicas foram definidas e se repetem para todas as documentações (na imagem à esquerda, exemplo do título de eleitor), de acordo com o princípio de unidade descrito por Petterson (2002; 2016). As 
questões descritas são: “Por que é importante?”, “Como emitir?”, “Quanto custa?”, “Quais os documentos necessários?”, “Outras informações importantes”, “Ainda tem dúvidas?”.

Figura 3: Tela de detalhes: "Título de eleitor".
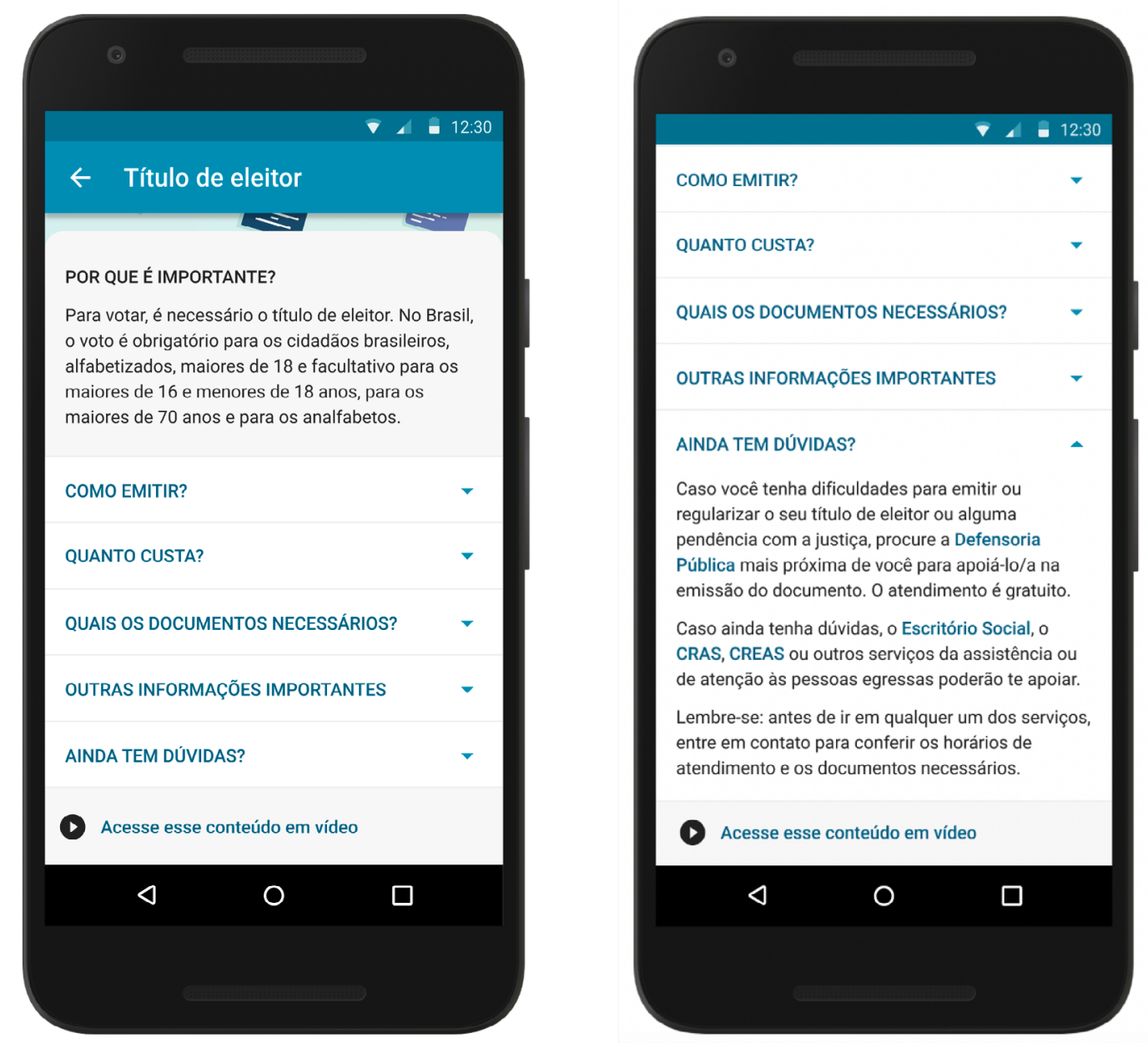

As cinco primeiras questões trazem as respostas às perguntas levantadas. A penúltima traz informações relevantes que não cabem às questões anteriores. Já a última (imagem à direita), informa ao usuário serviços que ele deve buscar em caso de dúvidas que não puderam ser resolvidas apenas com o uso do aplicativo.

Com exceção da primeira questão, todas as demais são aplicadas em um accordeon que revela informação com um clique. O objetivo é enfatizar as questões e facilitar o acesso apenas à informação desejada, sem que o usuário se perca em uma grande massa de texto. A primeira pergunta não possui o comportamento de accordeon a fim de prover ênfase para essa informação. Conforme afirma Petterson (2016), a ênfase pode ser empregada para atrair e manter a atenção do usuário. Nesse caso, espera-se que todos os usuários alfabetizados tenham ciência do porquê é importante a emissão/regularização de determinada documentação e, consequentemente, se interessem em acessar as demais questões a fim de sanar suas dúvidas e garantirem o acesso a seus documentos. 
No fim das questões, é apresentado para o usuário também link para vídeo representativo do mesmo conteúdo, que pode ser acessado em casos de dificuldade de leitura ou preferência pessoal. É importante ressaltar que muitos dos egressos que compõem o público-alvo não dispõem de condições financeiras para adquirirem bens de consumo de preço elevado, de forma que utilizam dispositivos móveis de gerações ultrapassadas. Por isso, o aplicativo visa ser o mais 'leve' possível, deixando conteúdos mais 'pesados', como vídeos, para acesso externo ao app. Nesse caso, clicando no link para acesso ao conteúdo em vídeo, o usuário acessa em uma modal a visualização do vídeo hospedado na plataforma YouTube.

Além disso, é importante observar também que, por consumir grande quantidade de dados móveis, dados esses que podem ser limitados para os egressos também por restrições financeiras, o aplicativo emite um aviso para o usuário caso ele não esteja conectado à uma rede wi-fi (Figura 4).

Figura 4: Modal de aviso de uso de dados móveis.

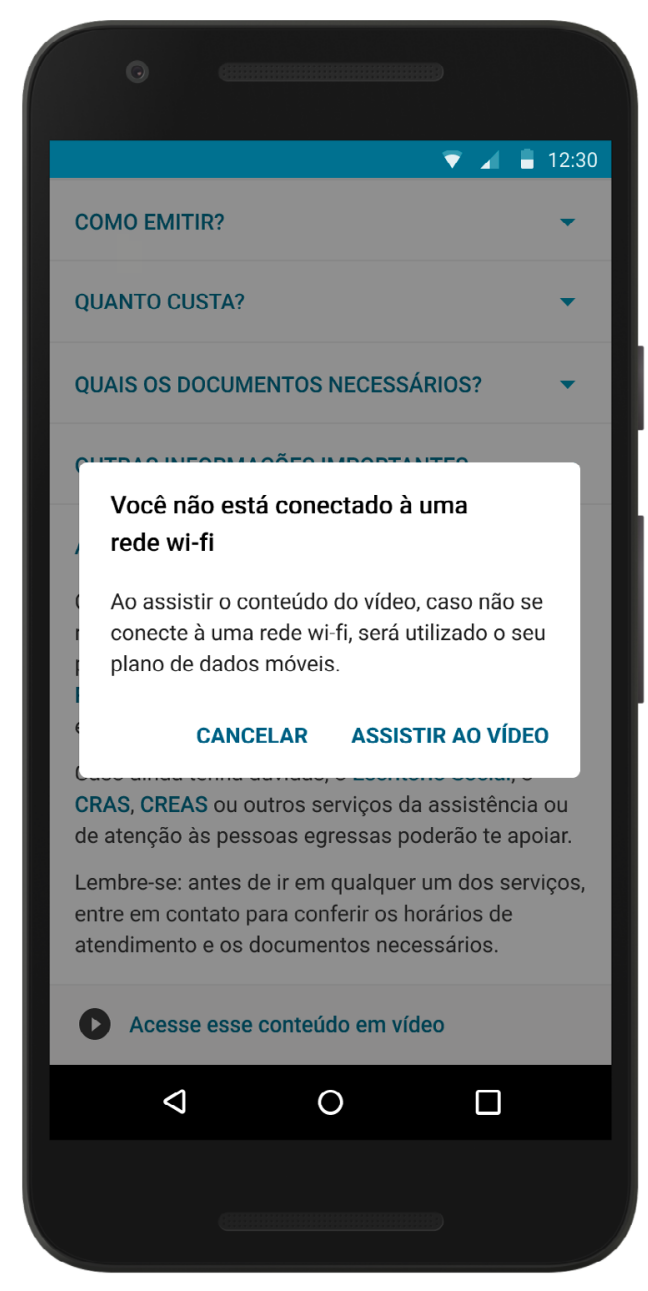

Por fim, caso o usuário clique em um dos links de outros serviços, como por exemplo, a Defensoria Pública (Figura 3), será direcionado para uma nova funcionalidade denominada "Assistência jurídica gratuita", que traz as informações gerais da defensoria (Figura 5). 
Figura 5: Tela inicial da funcionalidade "Assistência jurídica gratuita".
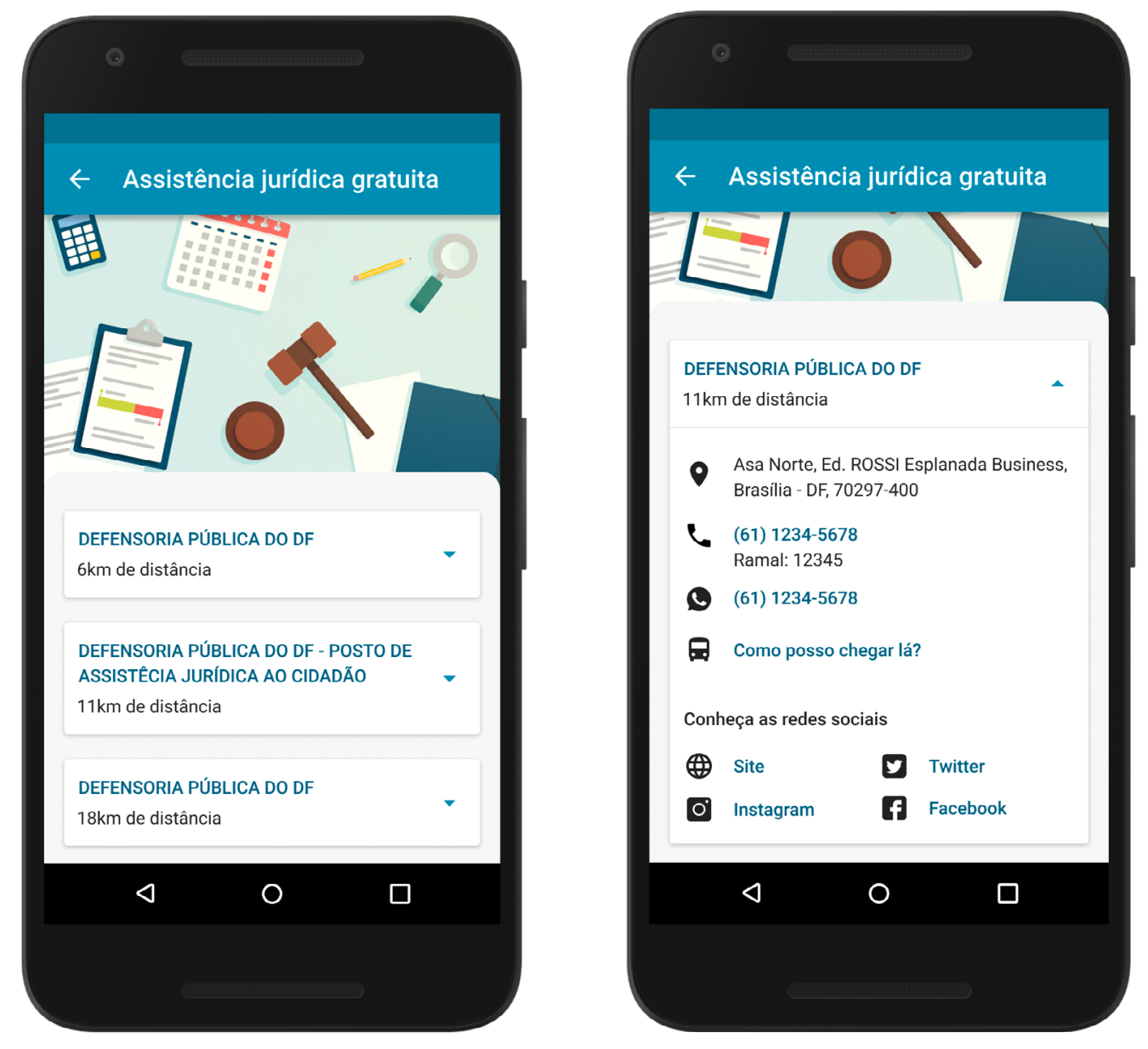

É importante ressaltar que, caso o usuário permita o uso da sua localização precisa, terá acesso à listagem de estabelecimentos por ordem de proximidade, além da informação de qual a sua distância atual para o local em questão. Caso opte por não compartilhar a localização, deverá informar a cidade na qual se encontra e acessar a listagem em ordem alfabética, sem a informação da distância por proximidade.

Respeitando o princípio administrativo de Petterson (2016), o aplicativo busca facilitar o acesso à informação para o usuário, fornecendo links que automatizam a busca pelo endereço, a ligação de telefone, o contato via WhatsApp e o acesso às redes sociais. Além disso, o aviso inicial da tela reforça ao usuário a necessidade de contato com o estabelecimento antes da visita ao local, a fim de garantir o sucesso no atendimento.

\section{Testes de usabilidade}

Após o desenvolvimento de protótipos funcionais, foram convidados três egressos para testes de usabilidade do aplicativo. Todos os egressos eram alfabetizados e possuíam familiaridade com o uso de aplicativos móveis. Os testes tiveram como objetivo avaliar se as interações propostas para o aplicativo eram de fácil de navegação e se as informações compartilhadas eram de fácil compreensão. 
Os testes foram feitos de maneira online com cada egresso separadamente, utilizando a plataforma Google Meets. Além do egresso, estavam presentes dois pesquisadores do projeto, um interagindo diretamente com o usuário e outro tomando notas, além de um desenvolvedor, responsável pela gravação consentida do teste.

Os egressos compartilharam as telas de seus dispositivos móveis, o que permitiu o acompanhamento em tempo real dos pesquisadores. Foi solicitado que os egressos realizassem 6 tarefas (classificadas pelos pesquisadores como fáceis ( 3 tarefas), médias ( 2 tarefas) ou difíceis ( 1 tarefa)) e verbalizassem em voz alta seus pensamentos, conforme sugerido por Steve Krug (2014). Essa ação permitiu que os pesquisadores tivessem melhor compreensão acerca do que motivou o caminho percorrido pelos usuários na navegação pelo aplicativo, assim como das dúvidas que surgiram e como eles foram capazes de solucioná-las utilizando as funcionalidades disponíveis. Para os três egressos participantes, a execução das tarefas ocorreu de maneira rápida e fácil, o que indica fácil interação e boa distribuição de informações.

Porém, devido a restrições impostas pela pandemia resultante da COVID-19, não foi possível testar com grupos mais vulneráveis, com pouca ou nenhuma familiaridade com aplicativos móveis, ou com baixo ou nenhum nível de alfabetização. Por isso, até o lançamento da primeira versão do aplicativo, não foi comprovada a eficiência das funcionalidades propostas para esse público.

\section{Considerações finais}

Neste artigo, procuramos responder como o um sistema interativo pode apoiar o egresso em seu processo de ressocialização, com especial foco no processo de emissão e/ou regularização de sua documentação. Porém, é preciso também ressaltar que, embora o aplicativo aqui apresentado esteja disponível gratuitamente nas lojas Google Play e App Store, nem todos os egressos terão acesso a um aplicativo móvel com acesso à internet para fazerem o download e explorarem suas funcionalidades. Além disso, a divulgação depende de iniciativa pública com direcionamento eficaz para seu público-alvo. Caso essa divulgação não se materialize ou não tenha força necessária, é possível que o público egresso não acesse o aplicativo por falta de conhecimento da solução.

Vale também ressaltar que, embora o aplicativo busque atender aos egressos de maneira eficaz, existem serviços que não podem ser materializados no próprio aplicativo, de forma que a solução se resume em trazer informações de que facilitem o entendimento e o acesso dos egressos ao serviço final. Ainda assim, acredita-se que as soluções propostas poderão ter grande impacto para o público-alvo.

Por fim, embora o aplicativo tenha sido apresentado como uma proposta de design aplicado ao apoio ao egresso no processo de ressocialização, acredita-se que o design tem potencial para auxiliar na proposição e desenvolvimento de diversas outras propostas que possam auxiliar o egresso, em suas mais distintas dificuldades. 


\section{Referências}

Almeida, O. L., Paes-Machado, E. (2013). Processo sociais de vitimização prisional. Tempo Social, revista de sociologia da USP, v. 25, n.1, 257-286. https://doi.org/10.1590/S010320702013000100013

Assis, R. D. (2007). A realidade atual do sistema penitenciário brasileiro. Revista CEJ, ano XI, $n^{\circ} 39,74-78$.

Brasil. Ministério da Justiça e Segurança Pública (2017). Levantamento Nacional de Informações Penitenciárias - Atualização. Departamento Penitenciário Nacional. Disponível em: https://www.gov.br/depen/pt-br/sisdepen/mais-informacoes/relatorios-infopen/relatoriossinteticos/infopen-jun-2017.pdf (último acesso em 18/04/2021)

Brasil. Ministério da Justiça e Segurança Pública (2020). Levantamento Nacional de Informações Penitenciárias. Departamento Penitenciário Nacional. Disponível em: https://app.powerbi.com/view?r=eyJrljoiMjU3Y2RjNjctODQzMi00YTE4LWEwMDAtZDIzNWQ 5YmlzMzk1 liwidCI6ImViMDkwNDIwLTQ0NGMtNDNmNy05MWYyLTRiOGRhNmJmZThIMSJ 9 (último acesso em 18/04/2021)

Brasil. Senado Federal (2017). Código Penal - Decreto-lei nº 2.848/1940. Coordenação de Edições Técnicas. Disponível em: https://www2.senado.leg.br/bdsf/bitstream/handle/id/529748/codigo_penal_1ed.pdf (último acesso em 18/04/2021)

Carvalho Filho, M. J. (2012). Sujeitos da fronteira - A saída da prisão. Orgs. Prisões numa abordagem interdisciplinar [online]. Salvador: EDUFBA, 179-195. http://books.scielo.org/id/7mkg8/pdf/coelhos-9788523217358-12.pdf (último acesso em 18/04/2021)

Cassiano, C. V. (2017). Da pena de multa, sua importância e do juízo competente para sua execução. Reju - Revista Jurídica, v. 4, no 1.

Coates, K., Ellison, A. (2014). An introduction to information design. London, Laurence King Publishing Ltd.

Ferreira, E. M., Oliveira, H. C. S., Vieira, K. (2020). Estou livre, e agora? Guia para egressos e egressas do sistema prisional. Instituto Humanitas 360. Disponível em:

https://humanitas360.org/project/guia-para-egressos-e-egressas-do-sistema-prisional/ (último acesso em 18/04/2021)

Figueiró, R. A., Dimenstein, M. (2016). Castigo, gestão do risco e da miséria: Novos discursos da prisão na contemporaneidade. Estudos de psicologia, 21, 192-203. http://dx.doi.org/10.5935/1678-4669.20160019

Fischer, R. M., Abreu, S. F. A. (1987). Políticas penitenciárias, um fracasso?. Lua Nova: Revista de cultura e política, vol. 3 no 4, 70-79. https://doi.org/10.1590/S0102-64451987000200012

Internacional Institute of Information Design - IIID (2000). What is Information Design? https://www.iiid.net/home/definitions/ (último acesso em 18/04/2021)

Mergulhão, M. F. D. (2005). Pena de Multa. Programa de Pós-Graduação em Direito, Universidade Cândido Mendes. 
Monteiro, F. M., Cardoso, G. R. (2013). A seletividade do sistema prisional brasileiro e o perfil da população carcerária - um debate oportuno. Civitas, v.13, $n^{\circ} 1$, 93-117. https://doi.org/10.15448/1984-7289.2013.1.12592

Petterson, R. (2002). Information design: an introduction. John Benjamins Publishing Company. (2016). Information design theories. IIID Public Library.

Rogers, Y., Sharp, H., Preece, J. (2013). Design de interação - Além da interação humanocomputador. $3^{a}$ edição. Tradução de Isabela Gasparini. Bookman.

Sapori, L. F., Santos, R. F., Maas, L. W. D. (2017). Fatores sociais determinantes de reincidência criminal no Brasil: o caso de Minas Gerais. RBCS, vol. 32, nº 94, e329409. ISSN 1806-9053. https://doi.org/10.17666/329409/2017

Krug, S. (2014). Não me faça pensar: atualizado. Alta Books, edição atualizada.

Wacquant, L., (2003). Punir os pobres. Editora Revan.

\section{Sobre os autores}

Emille Catarine Rodrigues Cançado, Mestranda, UnB, Brasil <catarine.emille@gmail.com> Tiago Barros Pontes e Silva, Dr., UnB, Brasil <tiagobarros@unb.br> Ana Mansur de Oliveira, Dra., UnB, Brasil <anamansur@gmail.com> Virginia Tiradentes Souto, Dra., UnB, Brasil <v.tiradentes@gmail.com> Edna Dias Canedo, Dra., UnB, Brasil <edna.canedo@gmail.com> 